\title{
Motorcycle Related Oral and Maxillofacial Injuries Seen at Komfo Anokye Teaching Hospital, Kumasi-Ghana
}

\author{
Alexander Oti Acheampong1 ${ }^{*}$, Merley Newman-Nartey², Solomon Obiri-Yeboah ${ }^{1}$, Jonathan Mensah ${ }^{3}$, \\ Ama Amuasi', Daniel Sabbah', Jonathan Olesu', Elijah Ebenezer Asamoah', \\ Robert Nii Lamy Larmie3 ${ }^{3}$, Peter Donkor ${ }^{1}$
}

\author{
${ }^{1}$ School of Medicine and Dentistry, Kwame Nkrumah University of Science and Technology, Kumasi, Ghana \\ ${ }^{2}$ School of Medicine and Dentistry, University of Ghana, Accra, Ghana \\ ${ }^{3}$ KomfoAnokye Teaching Hospital, Kumasi, Ghana \\ Email: ^aotiacheampong@yahoo.com
}

How to cite this paper: Acheampong, A.O., Newman-Nartey, M., Obiri-Yeboah, S., Mensah, J., Amuasi, A., Sabbah, D., Olesu, J., Asamoah, E.E., Larmie, R.N.L. and Donkor, P. (2019) Motorcycle Related Oral and Maxillofacial Injuries Seen at Komfo Anokye Teaching Hospital, Kumasi-Ghana. Surgical Science, 10, 106-112. https://doi.org/10.4236/ss.2019.103014

Received: February 16, 2019

Accepted: March 19, 2019

Published: March 22, 2019

Copyright $\odot 2019$ by author(s) and Scientific Research Publishing Inc. This work is licensed under the Creative Commons Attribution-NonCommercial International License (CC BY-NC 4.0). http://creativecommons.org/licenses/by-nc/4.0/ (c) (i) (8) Open Access

\begin{abstract}
Background: Motorcycle related injuries have become a major public health problem because the increased use of motorcycles has been accompanied with a corresponding increase of road traffic accidents. Objective: The purpose of this study was to evaluate the occurrence of oral and maxillofacial injuries associated with motorcycles as seen at the second largest Teaching Hospital in Ghana, the Komfo Anokye Teaching Hospital (KATH). Method and Materials: The compiled data that were reviewed for this retrospective study were obtained from the Accident and Emergency unit of KATH. These comprised 135 successive maxillofacial trauma patient records entered from August 2017 to August 2018. Results: Total number of road traffic related injuries seen at OMFS was 135 during the study period. Out of this number, 66 were related to motorcycle injuries. This represented $48.7 \%$ of the Road Traffic Accidents seen at oral and maxillofacial surgery department (OMFS). The age range was from 3 to 64 years. The average age was 26.7 years. 62 (93.9\%) were males and $4(6.1 \%)$ were females. $16(24.2 \%)$ of the motorcycle injuries were caused by the "Okada", 2 (3.0\%) by "Pragia" and 48 (72.8\%) by the "Aboboyaa". 46 (69.7\%) of the motorcycles victims were themselves the riders, 12 (18.2\%) were pedestrians and $8(12.1 \%)$ were passengers. There were 8 deaths. $6(75.0 \%)$ of the deaths were caused by the "Aboboyaa". "Okada" accounted for only 2 (15.0\%) deaths. Concerning the riders and the passengers, only 8 (14.8\%) of the victims were helmeted. The majority were unhelmeted (85.2\%). Conclusion: Motorcycle transportation is the cause of many oral and maxillofacial injuries. Majority of the victims suffered multiple facial bone fractures. Males were more often affected than females and the majority were unhelmeted.
\end{abstract}




\section{Keywords}

Motorcycle, Oral, Maxillofacial, Injuries, Kumasi

\section{Introduction}

Head and facial fractures are among the frequently affected parts of the body during road traffic accidents [1] to the extent that it has been reported that $20 \%$ $60 \%$ of all individuals involved in automobile accidents have some level of facial fractures [2] [3]. The face, being the most exposed part of the body, is particularly vulnerable to such injuries including injuries of victims of motorcycle accidents [3] [4] [5].

Motorcycle related injuries have become a major public health problem [6] because the increased use of motorcycles has been accompanied with a corresponding increase in road traffic accidents. The motorcycle is known as the most dangerous motor vehicle because for each mile that the vehicle travels, their riders have a 34-fold higher risk of death in an accident than people driving other types of vehicles and the likelihood of injury is eight times greater than other vehicles [7].

Motorcycle accidents are the most common cause of maxillofacial fractures in Brazil [8].

Head injuries have been reported to be the greatest cause of fatality in most motorcycle injuries in China [6]. The occurrence of bone fractures was high and most victims had a single injury; however the number of deaths associated with motorcycle accidents was very low [6].

In Nigeria, motorcyclist road traffic accidents were reported to be more common in young male individuals [7].

Ghanaian laws are against motorcycle use for commercial transportation. The Road Traffic Act (Act 683), passed in 2004 by the Parliament of Ghana, precludes the use of motorcycles for commercial purposes or to carry fare-paying passengers in the country. Act 683, which prescribes a fine or a term of imprisonment or both for persons who contravene, was aimed at improving and maintaining safety for all modes of road transportation in the country. Despite this law, there has been an increase in commercial transportation using motorcycles.

The purpose of this study was to evaluate the occurrence of oral and maxillofacial injuries associated with motorcycles as seen at the second largest Teaching Hospital in Ghana, the Komfo Anokye Teaching Hospital (KATH).

\section{Materials and Methods}

The compiled data that were reviewed for this retrospective study were obtained from the Accident and Emergency unit of KATH. These comprised of 135 successive maxillofacial trauma patient records entered from August 2017 to August 2018. The injuries of sixty-six (48.7\%) of these individuals involved in road traffic accidents involved motorcycles. Information collected included demographic features, vehicle type, the use of helmets, whether the patient was a rider, pas- 
senger or pedestrian, extent of bony fracture or soft tissue injury and whether the injury was fatal. The data was anonymised and de-identified prior to analysis. Ethical approval was sought from Komfo Anokye Teaching Hospital and Kwame Nkrumah University of Science and Technology committee on human research and publications and ethics (CHRPE).

In data analysis, descriptive and inferential statistical techniques were used. The statistical techniques involved obtained absolute distributions, percentages and statistical measures. The statistical program used was the SPSS software (Statistical Package for the Social Sciences) version 18.

\section{Results}

Total number of road traffic related injuries seen at OMFS was 135 during the study period. Out of this number, 66 were related to motorcycle injuries. This represented $48.7 \%$ of the Road Traffic Accidents seen at OMFS. The age range was from 3 to 64 years. The average age was 26.7 years. 62 (93.9\%) were males and $4(6.1 \%)$ were females. $16(24.2 \%)$ of the motorcycle injuries were caused by the "Okada", 2 (3.0\%) by "Pragia" and $48(72.8 \%)$ by the "Aboboyaa". 46 (69.7\%) of the motorcycles victims were themselves the riders, 12 (18.2\%) were pedestrians and $8(12.1 \%)$ were passengers. Majority (86.0\%) sustained both bony and soft tissue injuries and only $14.0 \%$ had only soft tissue injuries. Those with bone fractures, $56.4 \%$ had multiple facial bone fractures and $43.6 \%$ sustained single facial bone fracture. Soft tissue injuries were debrided and sutures and bone fractured managed using open reduction and internal fixation. All patients were given analgesics and antibiotics.

There were 8 deaths. 6 (75.0\%) of the deaths was caused by the "Aboboyaa". "Okada" accounted for only 2 (15.0\%) deaths. Concerning the riders and the passengers, only $8(14.8 \%)$ of the victims were helmeted. The majority were unhelmeted (85.2\%). $75 \%$ of the victims suffers multiple facial bone fractures in addition to various degrees of soft tissues injuries as seen in Figure 1 and Figure 2.

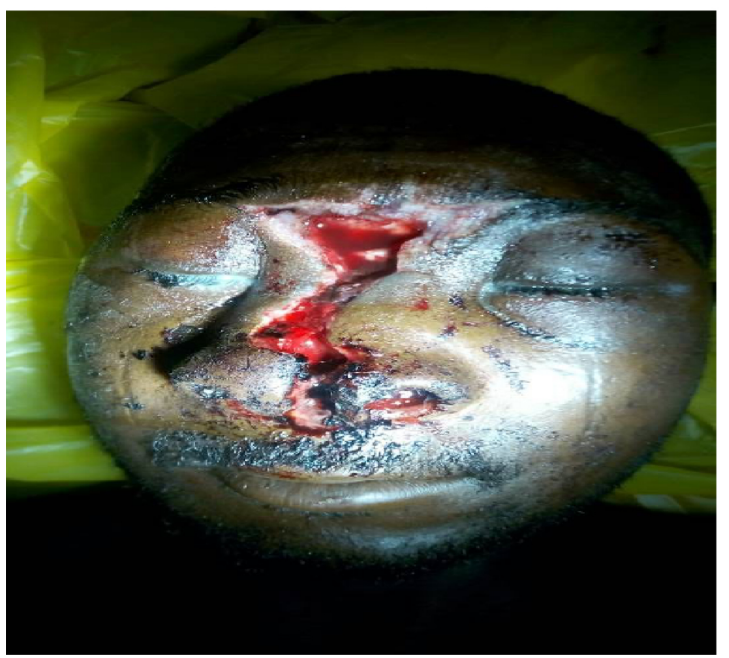

Figure 1. Patient with multiple facial fractures. 


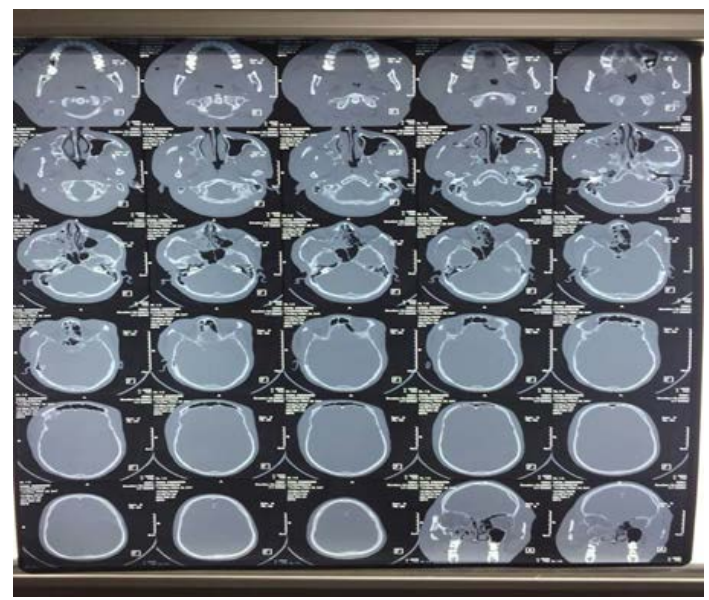

Figure 2. CT-Scan of patient with multiple facial fractures.

\section{Discussion}

Motorcycle transportation has become very popular in the nation over the past five years. Presently, motorcycle taxis provide urban public transportation services alongside those offered by minivans (trotros) and shared taxis in some parts Ghana especially in the cities of Kumasi, Accra, Tamale and some market centres in the regional capitals of Ghana.

It is believed that motorcycle transportation has become very popular around 2005 and 2007 when Nigerian films became popular in Ghana. Actors in those movies used motorcycles as a means of transportation which resulted in Ghanaians taking up this economical and convenient means of urban transportation called the "Okada" (Figure 3).

The popularity of motor tricycles also increased around the 2010 from the widespread viewing of Indian movies. These motor tricycles are normally used for urban transportation of both humans ("Aboboyaa", Figure 4) and goods (“Pragia” Figure 5).

In this present study, motorcycles accounted for most (48.7\%) of all road traffic injuries seen in the OMFS unit of the hospital. This finding was similar to a study in Nigeria where motorcycle injuries accounted for $69.0 \%$ of all trauma cases seen in a teaching hospital [4]. This could be due to the increase usage of motorcycle taxis in and around the Kumasi metropolis where the KATH hospital is situated. The growing number of motorcycles could be attributed to the unreliability and high cost of public transportation [8] according to a related study. The low cost, easy maintenance and low fuel consumption has continued to favour an increase in motorcycle transportation.

Motorcyclists are particularly vulnerable to injury because there is little or no protection provided in the event of a collision. Majority of the victims were males. This could be explained by the tendency of riders and passengers of these "Okadas" to be males. This observation is similar to a study in Nigeria [5].

The average age of 26.7 years was also consistent with several studies [4] [9] 


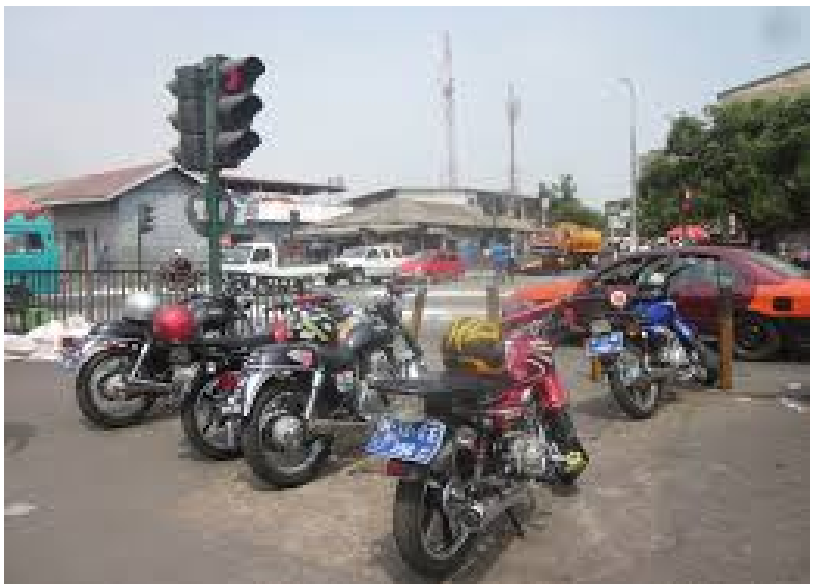

Figure 3. "Okada” transporting humans.

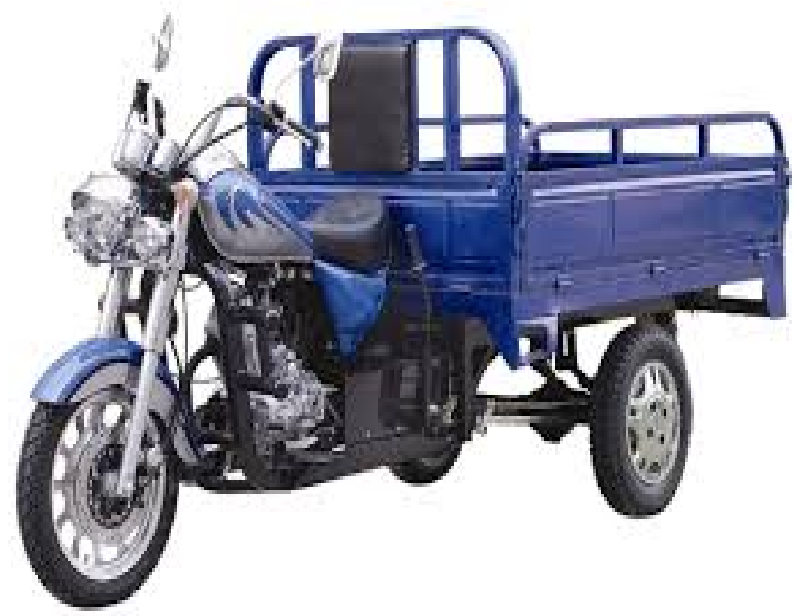

Figure 4. "Aboboya" carrying humans and goods.

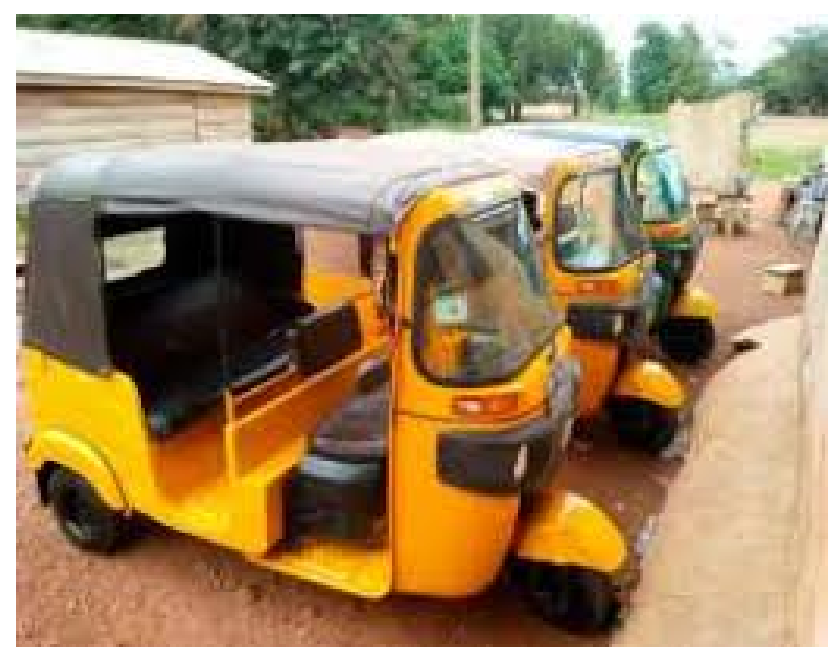

Figure 5. "Pragia" transporting humans.

[10]. This may be due to the tendency of males of this age to be very active in their use of the services of the motorcycle taxis for various commercial activities 
including the transportation of goods. Majority of the injuries were associated with the "Aboboyaa" motor tricycles. This type of motorcycle is used to transport both humans and goods. The high prevalence of injuries could be due to the lack of use of motorcycle helmets, bad road conditions, negligence and recklessness while driving or inadequate traffic law enforcement by police. They also tend to be over loaded and travel for longer distances compared to the "Pragia", which may explain the high involvement of motor tricycles in road traffic accidents.

In this study, the number of deaths was very low. A previous study in Brazil showed that the majority of patients died on the scene, followed by a consistent decrease in fatalities during the post-traumatic period [11].

Most of the victims suffered multiple facial bone fractures (Figure 1 and Figure 2) similar to a study in Nigeria [8] because the majority tended to be unhelmeted and unprotected as pertains in conventional vehicles. In a related study, $40 \%$ of the victims were not properly helmeted [8] [12]. Helmets demonstrate a protective effect and may be an effective public health intervention to significantly reduce the burden of traumatic brain injury [13]. The "Aboboyaa" also tend not to have good balance especially when they are over loaded and particularly when the rider is not well trained.

\section{Conclusion}

Motorcycle transportation is the cause of many oral and maxillofacial injuries. Majority of the victims suffered multiple facial bone fractures. Males were more affected than females and the majority were unhelmeted. "Aboboyaa" was the major cause of motorcycle related injuries.

\section{Recommendations}

Motorcycle transportation in Ghana is on the ascendency. It is known that the operators of these vehicles do not have the requisite license and training to engage in the commercial use of these motorcycles. The government should take a second look at the law. The laws could be enforced to stop the commercialization of motorcycles on our roads or amended to allow for their safe usage to decrease the prevalence of motorcycle related road traffic accidents.

\section{Limitation of Study}

Some of the patients could not afford the high cost of CT-Scan. This affected comprehensive assessment of the extent of bone injuries in some of the patients. The mechanism of injuries was not available in the patient's notes.

\section{Conflicts of Interest}

None to be declared.

\section{References}

[1] Adeyemo, W.L., Ladeinde, A.L., Ogunlewe, M.O. and James, O. (2005) Trends and 
Characteristics of Oral and Maxillofacial Injuries in Nigeria: A Review of the Literature. Head \& Face Medicine, 1, 7. https://doi.org/10.1186/1746-160X-1-7

[2] Cavalcanti, A.L., et al. (2014) Head and Maxillofacial Injuries in Child and Adolescent Victims of Automotive Accidents. Scientific World Journal, 2014, Article ID: 632720. https://doi.org/10.1155/2014/632720

[3] Lin, M.-R. and Kraus, J.F. (2009) A Review of Risk Factors and Patterns of Motorcycle Injuries. Accident Analysis \& Prevention, 41, 710-722. https://doi.org/10.1016/j.aap.2009.03.010

[4] Obimakinde, O.S., Ogundipe, K.O., Rabiu, T.B. and Okoje, V.N. (2017) Maxillofacial Fractures in a Budding Teaching Hospital: A Study of Pattern of Presentation and Care. Pan African Medical Journal, 26, 218. https://doi.org/10.11604/pamj.2017.26.218.11621

[5] Taiwo, A., Godwin, N., Ibikunle, A. and Soyele, O. (2013) Facial Fracture Management in Northwest Nigeria. Journal of Surgical Technique and Case Report, 5, 65. https://doi.org/10.4103/2006-8808.128723

[6] Xiong, L. and Li, L. (2015) Single-Vehicle and Multi-Vehicle Accidents Involving Motorcycles in a Small City in China: Characteristics and Injury Patterns. AIMS Public Health, 2, 74-85. https://doi.org/10.3934/publichealth.2015.1.74

[7] Oginni, F.O., Ugboko, V.I., Ogundipe, O. and Adegbehingbe, B.O. (2006) Motorcycle-Related Maxillofacial Injuries among Nigerian Intracity Road Users. Journal of Oral and Maxillofacial Surgery, 64, 56-62.

https://doi.org/10.1016/j.joms.2005.09.027

[8] Seerig, L.M., Bacchieri, G., Nascimento, G.G., Barros, A.J.D. and Demarco, F.F. (2016) Use of Motorcycle in Brazil: Users Profile, Prevalence of Use and Traffic Accidents Occurrence-A Population-Based Study. Ciência \& Saúde Coletiva, 21, 3703-3710. https://doi.org/10.1590/1413-812320152112.28212015

[9] Ok, O. and Ao, A. (2012) Maxillofacial Fractures in Owo, South Western Nigeria. A 4 Year Retrospective Review of Pattern and Treatment Outcome. Dentistry, 2, 132-134. https://doi.org/10.4172/2161-1122.1000132

[10] Hashim, H. and Iqbal, S. (2011) Motorcycle Accident Is the Main Cause of Maxillofacial Injuries in the Penang Mainland, Malaysia. Dental Traumatology, 27, 19-22. https://doi.org/10.1111/j.1600-9657.2010.00958.x

[11] Abosadegh, M.M., Rahman, S.A. and Saddki, N. (2017) Association of Traumatic Head Injuries and Maxillofacial Fractures: A Retrospective Study. Dental Traumatology, 33, 369-374. https://doi.org/10.1111/edt.12349

[12] Cavalcanti, A.F.C., et al. (2017) Head and Face Injuries in Automobile Accidents and Associated Factors in a City in Northeastern Brazil. Pesquisa Brasileira em Odontopediatria e Clinica Integrada, 17, 3753. https://doi.org/10.4034/PBOCI.2017.171.30

[13] Gupta, S., et al. (2018) Impact of Helmet Use on Traumatic Brain Injury from Road Traffic Accidents in Cambodia. Traffic Injury Prevention, 19, 66-70.

https://doi.org/10.1080/15389588.2017.1342821 